\title{
Comparison of effect of Labetalol and fentanyl with only fentanyl for attenuating pressure responses to intubation and skull pin insertion in neurosurgery
}

\author{
Leena P. Patel ${ }^{1}$, Jenish C. Patel ${ }^{2, *}$, Keval P. Patel ${ }^{3}$, Chirag S. Rathva ${ }^{4}$, Vijeta Tandel ${ }^{5}$ \\ ${ }^{1}$ Associate Professor, ${ }^{2}$ Junior Lecturer, ${ }^{3}{ }^{\text {rd }}$ year Resident, ${ }^{4} 1^{\text {st }}$ year resident, ${ }^{5} 2^{\text {nd }}$ year resident , Dept. of Anaesthesia, Gujarat \\ Cancer and Research Institute, B.J. medical college, Ahmedabad, Gujarat, India
}

*Corresponding Author:

Email: jenishvimal@gmail.com

Received: $30^{\text {th }}$ September, 2017

Accepted: $24^{\text {th }}$ November, 2017

\begin{abstract}
Introduction: Laryngoscopy and intubation as well as application of skull pin in neurosurgical procedure is a highly noxious stimulus which causes hemodynamic changes and can be detrimental in patients with raised intracranial pressure. We studied the effect of addition of intravenous labetalol with fentanyl to attenuate the pressure response to intubation and skull pin insertion in neurosurgery.

Materials and Methods: Fifty patients undergoing elective neurosurgical procedure were randomised into two groups as group LF and group F. Patients of group LF received intravenous Labetalol $0.25 \mathrm{mg} / \mathrm{kg} 5$ minutes prior and intravenous fentanyl $2 \mu \mathrm{g} / \mathrm{kg}$ 3 minutes prior to intubation. Patients of group F received intravenous saline 5 minutes prior and intravenous Fentanyl $2 \mu \mathrm{g} / \mathrm{kg} 3$ minutes prior to intubation. Heart rate (HR) systolic and diastolic blood pressure (SBP and DBP) and mean arterial pressure (MAP) were noted at baseline, after study drug administration, after induction, immediately after intubation, immediately after skull pin insertion, 5 minutes interval till 20 minutes after that.

Results: Immediately after intubation HR was $82.60 \pm 5.0$ per minute in LF group and $97.64 \pm 4.71$ per minute in group $\mathrm{F}$ $(\mathrm{p}=0.01)$. MAP was higher in group $\mathrm{F}$ than group $\mathrm{LF}(106.84 \pm 3.89 \mathrm{~mm}$ of $\mathrm{Hg}, 83.02 \pm 3.75 \mathrm{~mm}$ of $\mathrm{Hg}$ respectively $\mathrm{p}=0.001)$. Immediately after skull pin insertion rise in HR (group LF $79.76 \pm 5.07$ per minute, group F $97.84 \pm 4.40$ per minute respectively $\mathrm{p}=0.001$ ) and MAP ( group LF $80.28 \pm 5.32 \mathrm{~mm}$ of $\mathrm{Hg}$, group F $103.17 \pm 7.66 \mathrm{~mm}$ of $\mathrm{Hg}$ respectively p=0.001) was at lesser extent in group LF.

Conclusion: Addition of single dose intravenous labetalol to fentanyl gives better haemodynamic stability to laryngoscopy and intubation as well as skull pin insertion than fentanyl alone.
\end{abstract}

Keywords: Skull pins, Labetalol, fentanyl, Hemodynamic changes, Pressure response.

\section{Introduction}

Tracheal intubation is necessary for general anaesthesia for major surgeries which is highly noxious stimulus and shown to increase bispectral index (bis) and entropy indices during anaesthesia. The increase in bis has also been demonstrated following skull pin application. ${ }^{1}$ Mayfield or sugita holder metallic pins are inserted through the scalp and periosteum into the external lamina of the skull and are tightened to stabilise the head during neurosurgery. It is intensely painful and gives a strong nociceptive stimulus even under deep anesthesia leading to sudden hemodynamic changes which can cause increase in intracranial pressure, brain edema, rupture of aneurysm, intracranial haemorrhage, myocardial infarction, arrhythmia, pulomanry edema, etc. ${ }^{2,3}$ In patients with impaired cerebral auto-regulation, this may result in a sudden increase in cerebral blood flow and volume precipitating intracranial hypertension. Different methods and modalities are in use to attenuate haemodynamic response to intubation as well as skull pin insertion including local anaesthetic infiltration at the pin sites on the scalp, ${ }^{4}$ scalp nerve blocks, ${ }^{1}$ deepening the plane of anaesthesia, opioids, dexmedetomidine, ${ }^{3}$ clonidine, ${ }^{5}$ alpha agonists, beta blockers and gamma-aminobutyric acid agonists. ${ }^{6,3}$
Each has its own pros $\mathrm{n}$ cons and side effects like interference in neurological evaluation, time consuming, affecting cerebral auto regulation. It is essential to provide optimal anesthesia while maintaining haemodynamic stability to avoid dangerous cardiovascular and neurological complications in patient with already compromised intracranial compliance and cerebral auto regulation. Opiod analgesics are widely used because they provide a good haemodynamic stability against surgical stimuli without causing a severe change in cerebrospinal fluid pressure and cerebral perfusion. ${ }^{7,8}$ But narcotics alone are not sufficient to prevent a haemodynamic response to skull pin insertion. ${ }^{9}$ So there is a need to combine other drug with fentanyl.

Labetalol is an antihypertensive alpha-1, beta- 1 and beta-2 adrenergic antagonist agent. ${ }^{10}$ It lowers the blood pressure by decreasing systemic vascular resistance (alpha-1 blockade) whereas reflex tachycardia triggered by vasodilation is attenuated by simultaneous betablockade and cardiac output remains unchanged. ${ }^{11}$ It has better safety profile and haemodynamic stability. Hence, Labetalol may be the drug of choice to attenuate the adrenergic response to laryngoscopy and intubation as well as skull pin insertion in patients undergoing neurosurgery. Studies on hemodynamic response to 
skull pin insertion and on the use of labetalol to suppress that are lacking. Literature regarding use of labetalol in this group of patients is not much. Previously labetalol has been used effectively to blunt haemodynamic response to laryngoscopy and intubation. ${ }^{12}$ In the present randomised, prospective study we evaluated efficacy of addition of single bolus dose of Labetalol to fentanyl for attenuating haemodynamic stress responses to laryngoscopy and intubation as well as skull pin insertion in patients undergoing neurosurgery under general anesthesia. As a part of balanced anaesthesia we used fentanyl. Fentanyl being a potent synthetic opioid agonist decreases SBP and heart rate because of its vasodilation and analgesic property and direct stimulation of vagal centre and depression of vasomotor centre. ${ }^{13}$

\section{Materials and Methods}

Fifty patients of either sex, aged between 18-65 years, weighing $40-70 \mathrm{~kg}$, belonging to ASA grade I and ASA grade II undergoing elective neurosurgery under general anaesthesia and requiring pin insertion were enrolled for the study. All patients were divided into two groups, group LF and group $\mathrm{F}$ twenty five patients in each. Approval from the institutional ethics committee was taken and informed consent from the patient was obtained. Patients having history of drug allergy, hypertension, IHD, COPD, hepatic or renal diseases, emergency surgery, on $\beta$ blockers were excluded.

Preanaesthetic check up with all routine blood investigations with Chest $\mathrm{x}$-ray and ECG was done. Baseline heart rate (HR), systolic blood pressure (SBP) and diastolic blood pressure (DBP), mean arterial pressure (MAP) were recorded. Two IV lines were secured. Patients of Group LF received intravenous $0.25 \mathrm{mg} / \mathrm{kg}$ Labetalol diluted in $10 \mathrm{ml}$ saline 5 minutes prior and fentanyl $2 \mu \mathrm{g} / \mathrm{kg} 3$ minute prior to intubation. And patients of Group F received intravenous injection normal saline $10 \mathrm{ml} 5$ minutes prior to intubation and $2 \mu \mathrm{g} / \mathrm{kg}$ Fentanyl three minutes prior to intubation.

After preoxygenation Inj glycopyrrolate $(0.004 \mathrm{mg} / \mathrm{kg})$ was given. Patients were induced with thiopentone sodium $(5 \mathrm{mg} / \mathrm{kg})$ and vecuronium bromide $(0.1 \mathrm{mg} / \mathrm{kg})$. Intubation was done with $8.0 \mathrm{~mm}$ and $7.0 \mathrm{~mm}$ sized armoured endotracheal tube for male and female patients respectively by the same experienced anesthetist. Anesthesia was maintained with $\mathrm{O}_{2}: \mathrm{N}_{2} \mathrm{O}(50: 50), 1 \%$ sevoflurane and inj. vecuronium. Any increase in HR and MAP $>20 \%$ of baseline was treated with increase of sevoflurane concentration and bolus dose of propofol. HR, SBP, DBP and MAP were recorded immediately after loading doses of labetalol and fentanyl, after induction, after intubation, before pin insertion, immediately after pin insertion and 5, 10, $15,20 \mathrm{mins}$ after pin insertion. At the end of surgery neuromuscular block was reversed with injection neostigmine $0.05 \mathrm{mg} / \mathrm{kg}$ and injection glycopyrrolate $0.008 \mathrm{mg} / \mathrm{kg}$. Incidence of hypotension or bradycardia were recorded. Patients in which pin was not inserted within 5 minute after intubation were excluded from the study.

\section{Statistical Analysis}

Sample size was calculated with $80 \%$ of power analysis and $95 \%$ as confidence level and $10 \%$ as absolute error. SPSS version 17.0 was used for analysis. Datas of continous variable such as HR, SBP, DBP, MAP were expressed as mean \pm standard deviation. Data were analysed by student's paired t- test for between group comparison of values and unpaired t-test for within group variations. $\mathrm{P}<0.05$ values were considered significant.

\section{Observation and Results}

Both groups were comparable in patient characteristics with respect to age, weight and ASA physical status as shown inTable 1. $(\mathrm{p}>0.05)$ As shown in Table 2 the baseline HR in group LF and group $F$ were comparable $(p>0.05)$ which was decreased in both groups after loading with study drug.

As shown in Fig. 1 immediately after intubation HR increased in both groups but in group LF $(82.60 \pm$ $5.00)$ it was below base line whereas in group $F$ it $(97.64+4.71)$ was above base line with $p$ value (0.0001). Within two minutes HR came down to (80.73 $\pm 6.00,95.72 \pm 5.9$ ) in group LF and group $F$ respectively. At the time of pin insertion another spike was observed in HR in group F $(97.84 \pm 4.40)$ whereas in group LF it remain lower $(79.76+5.07)$.

As shown in Fig. 2 baseline value of SBP and DBP in group LF and group F were comparable. There was significant difference in SBP, DBP and MAP at immediately after intubation and at immediately after pin insertion. There was rapid fall in MAP two minutes after intubation. Again SBP rises immediately after pin insertion but was at lesser extent in group LF as compare to group $\mathrm{F}$. In group LF, SBP was $108.92 \pm 8.92$ while in group $F$ it was $133.2 \pm 9.11(p$ value 0.0001$)$. DBP in group LF was $70.92 \pm 5.23$ and in group F was $88.16 \pm 5.5$ (p value 0.0012 ).

As shown in Fig. 3 baseline values and values after loading doses of both groups were comparable $(\mathrm{p}>0.05)$. Immediately after intubation in group LF the MAP was $83.02+3.75$ while in group $F$ it was $106.84 \pm 3.89$ ( $p$ value 0.0001$)$. Immediately after pin insertion MAP was significantly higher in group $\mathrm{F}$ as compare to group LF. After pin insertion downwards trend was seen in both the groups. This favourable trend continued for around 20 minutes after pin insertion. None of the patients in both groups had any complication like bradycardia, hypotension, arrythmias or delayed recovery. 
Table 1: Patient Characteristics

\begin{tabular}{|l|c|c|c|}
\hline \multicolumn{1}{|c|}{ Characteristics } & Group LF & Group F & p-value \\
\hline Age & $48.44 \pm 13.78$ & $43.76 \pm 14.213$ & 0.24 \\
\hline Sex (Male/Female) & $15 / 10$ & $15 / 10$ & \\
\hline Weight & $63.64 \pm 9.50$ & $58.8 \pm 11.492$ & 0.11 \\
\hline
\end{tabular}

Data are expressed in Mean \pm SD, SD - Standard deviation

Table 2: Perioperative changes in the Heart Rate (HR)

\begin{tabular}{|l|c|c|c|}
\hline & $\begin{array}{c}\text { Group LF } \\
(\text { Mean } \pm \text { SD) }\end{array}$ & $\begin{array}{c}\text { Group F } \\
(\text { Mean } \pm \text { SD) }\end{array}$ & P Value \\
\hline Baseline & $89.56 \pm 7.69$ & $87.92 \pm 6.65$ & 0.4 \\
\hline After Loading Dose & $74.84 \pm 6.34$ & $79.08 \pm 5.55$ & 0.015 \\
\hline After Induction & $73.80 \pm 6.97$ & $87.12 \pm 4.53$ & $<0.05$ \\
\hline After Intubation & $82.60 \pm 5.00$ & $97.64 \pm 4.71$ & $<0.05$ \\
\hline 2 Min After Intubation & $80.73 \pm 6.0$ & $95.72 \pm 5.9$ & $<0.05$ \\
\hline At The Time Of Pin Insertion & $79.76 \pm 5.07$ & $97.84 \pm 4.40$ & $<0.05$ \\
\hline 5 Min After Pin Insertion & $72.00 \pm 3.60$ & $87.84 \pm 4.43$ & $<0.05$ \\
\hline 10 Min After Pin Insertion & $72.72 \pm 5.90$ & $86.84 \pm 4.30$ & $<0.05$ \\
\hline 15 Min After Pin Insertion & $71.89 \pm 6.34$ & $88.73 \pm 3.88$ & $<0.05$ \\
\hline 20 Min After Pin Insertion & $74.44 \pm 4.34$ & $85.68 \pm 4.92$ & 0.094 \\
\hline
\end{tabular}

Data expressed as Mean \pm SD

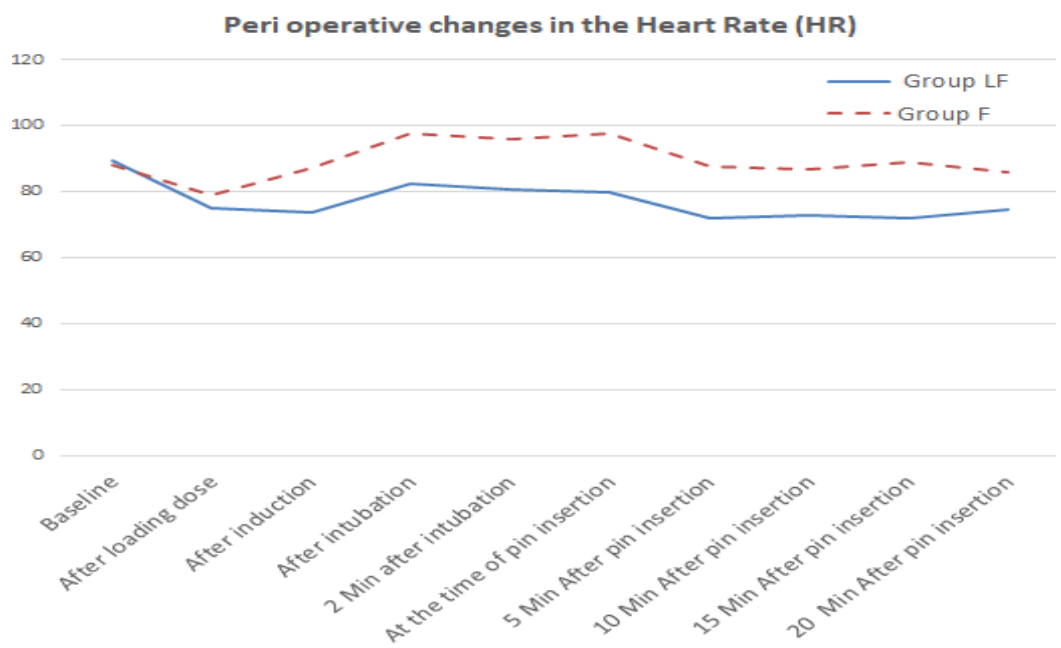

Fig. 1: Shows changes in the Heart Rate (HR)

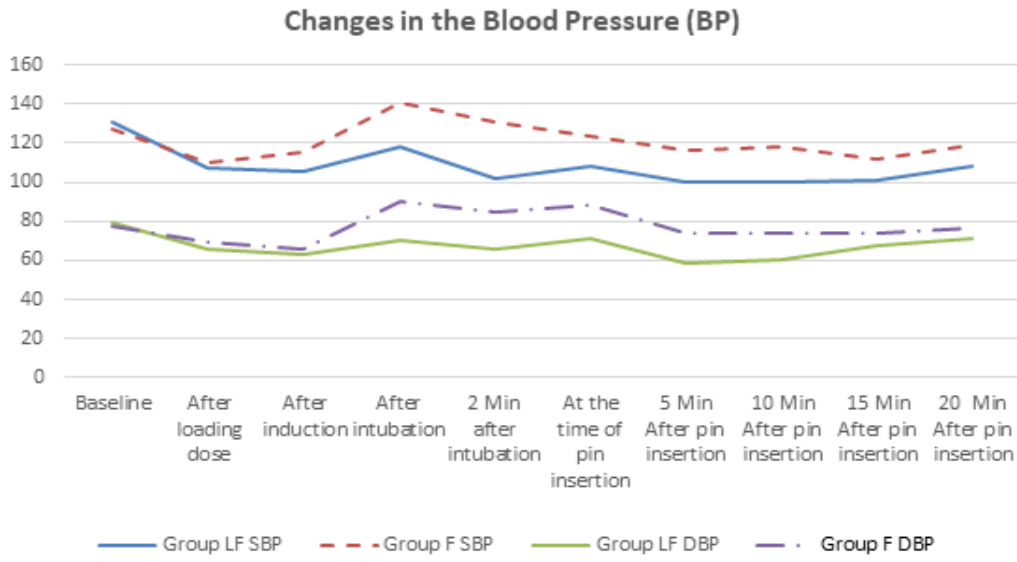

Fig. 2: Shows changes in the Systolic Blood Pressure (SBP) \& Diastolic Blood Pressure [DBP] 


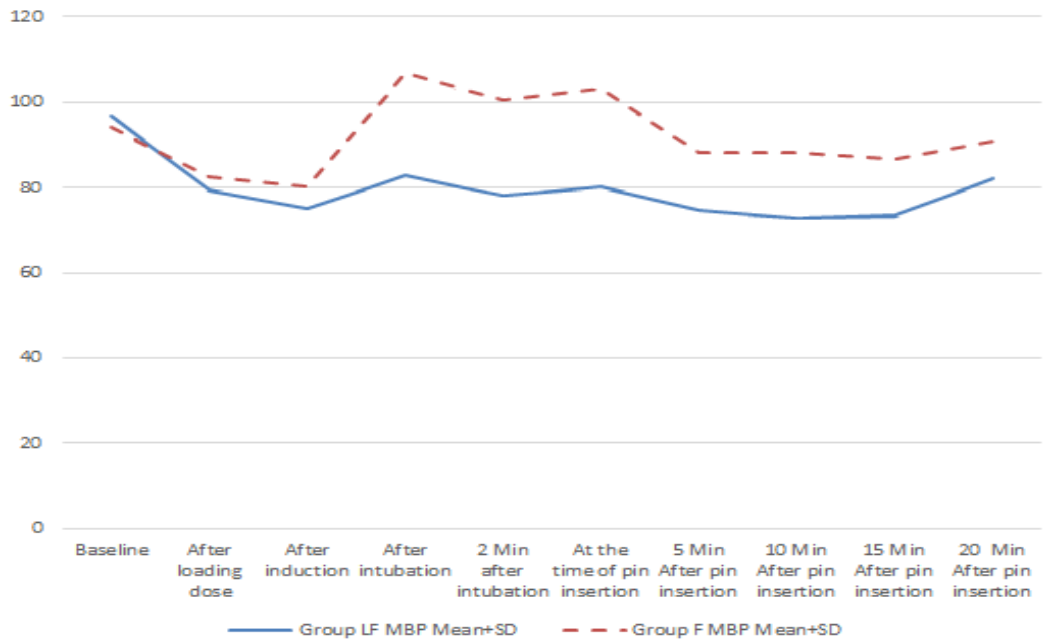

Fig. 3: Shows changes in Mean Arterial Pressure [MAP]

\section{Discussion}

The haemodynamic changes caused by airway manipulation are due to sympathoadrenal discharge from epipharyngeal and parapharyngeal stimulations which in turn causes a significant rise in the catecholamine level which increases blood pressure and pulse which may lead to cardiovascular complication and increased intracranial pressure. ${ }^{14}$ Many workers have used esmolol(cardio selective beta blocker), ${ }^{15}$ metoprolol, ${ }^{16,17}$ and Labetalol ${ }^{18,19,12}$ as a bolus and in infusion and found it to be effective to attenuate intubation responses, to prevent perioperative cardiovascular events and for haemodynamic stability.

Insertion of skull pins into the periosteum give rise to haemodynamic response and also causes increase in stress hormones which can affect outcome of the patient. ${ }^{17}$ Neurosurgical patients are with reduced intracranial compliance so even mild increase in cerebral blood flow can cause severe cerebral damage. In these situations the hemodynamic and metabolic effects on the human brain is important. Labetalol did not influence global or regional cerebral blood flow or cerebral oxygen metabolism and cerebral blood flow and auto regulation is presereved even with dose as high as $1 \mathrm{mg} / \mathrm{kg}^{20}$

We used $0.25 \mathrm{mg} / \mathrm{kg}$ labetalol before 5 minutes of intubation and found HR, SBP, DBP and MAP below baseline at all time including immediately after intubation and pin insertion. In group F HR and MAP was significantly raised but was within higher normal range suggesting that fentanyl also had attenuated pressure response but in labetalol group it was better controlled.

In consistant with our study Meftahuzzaman and et al studied labetalol and fentanyl and found significantly less increase in heart rate, systolic, diastolic, mean arterial pressures and RPP (rate pressure product) after intubation in group $\mathrm{L}$ and group $\mathrm{F}$ as compared to group C. They found minimum increase in group $\mathrm{L}$ and concluded that Labetalol is better agent for attenuation of laryngoscopic and intubation reflex. ${ }^{21}$

Similar to our study Survesh P. Singh ${ }^{22}$ and et al also had used labetalol $0.25 \mathrm{mg} / \mathrm{kg} 5 \mathrm{~min}$ prior to intubation and compared it with esmlol $0.5 \mathrm{mg} / \mathrm{kg}$ for haemodynamic response attenuation to laryngoscopy and intubation. They found Labetalol prevented the increase in SBP and MAP significantly. Labetalol had a significantly better control of HR and RPP was lower at all times as compared to control and esmolol group and RPP was below the critical 15000 mark in labetalol group. They found $28 \%$ of patients in the labetalol group had pulse rate less than 50 beats per minute after study period of 10 minute. It seems that when instrumentation stimulus is present Labetalol maintains the HR within normal range. When the effect of stimulus weans off, as occurs at $10 \mathrm{~min}$ post-intubation, the drug's effect takes over and pulse rates go below baseline values.

Here in our case a second stimulus in the form of pin insertion did not allow this taking over effect of Labetalol and in fact Labetalol covered the second stimulus too and maintained HR and BP throughout the study period.

We observed decrease in HR and MAP after study drug administration. In accordance to our study Babita and et $\mathrm{al}^{10}$ studied the effect of injection fentanyl $(2 \mu \mathrm{g} / \mathrm{kg})$ and injection labetalol $(0.25 \mathrm{mg} / \mathrm{kg})$ on sympathomimetic respose to laryngoscopy and intubation in vascular surgeries and found in decrease HR, SBP and DBP in both group before intubation due to effect of the drugs. The increase in HR and MAP after intubation was minimal in fentanyl and labetalol as compared with group C. They found HR and SBP significantly decreased below the baseline at 7 minutes. 
This might be because of the taking over effect of drug. Presynaptic alpha-2 receptors are spared by labetalol so that the released norepinephrine can continue to inhibit further release of catecholamines via the negative feedback mechanism resulting from the stimulation of alpha-1 receptors. Moreover this drug targets 5-10 times more specific beta blockade ${ }^{11,23}$ and prevent rebound hypertension and tachycardia. ${ }^{20,10}$

Researchers used Labetalol and nitroprusside to induce hypotension in major surgeries and showed that nitroprusside significantly increased the heart rate but cardiac output remain unchanged with labetalol administration. ${ }^{11}$ The arterial hypertension is due to increase in cardiac output rather than increase in systemic vascular resistance. $^{22}$

We used low doses of fentanyl because larger dose may leads to muscular rigidity, bradycardia, and postoperative respiratory depression. ${ }^{24}$ Chung et $\mathrm{al}^{25}$ had reported decrease in pressure response with a single dose of fentanyl $2 \mu \mathrm{g} / \mathrm{kg}$ given preoperatively. Fentanyl suppresses the haemodynamic response by increasing the depth of anaesthesia and decreasing the sympathetic discharge. ${ }^{26}$ Similar to our study Ayse Mizrak and et al found neither fentanyl nor local infilteration of lidocaine $2 \%$ scalp block alone could effectively suppress the $\mathrm{MAP}^{9}$ but, the combined use of both the drugs was able to suppress the MAP after pin fixation.

Bharne et $\mathrm{al}^{1}$ compared injection labetalol $0.25 \mathrm{mg} / \mathrm{kg}$ with scalp block for haemodynamic changes after skull pin insertion. Following Labetalol administration, HR decreased to $72.45 \pm 7.53 \mathrm{bpm}$. After pin application it increased to a maximum of $88.12 \pm 9.64 \mathrm{bpm}$ at $60 \mathrm{~s}$, after which a downward trend was seen. In group B on the other hand HR increased to $76.36 \pm 6.48 \mathrm{bpm}$ after scalp block and then pinning to a maximum of $82.18 \pm 7.13 \mathrm{bpm}$ at $60 \mathrm{~s}$. Block itself has caused mild increase in HR and MAP. After that MAP was better controlled with scalp block. Alka Kevalramani and et al had compared Labetalol and dexmedetomidine and found that changes in MAP were not significant statistically between group L and Group $\mathrm{D}(\mathrm{p}>0.05)$ at $\mathrm{I} 0, \mathrm{I} 1, \mathrm{I} 3, \mathrm{I}$, while fall in RPP was more in Group D as compared to group $\mathrm{L}(\mathrm{p}<0.001)$. Also the incidence of hypotension and bradycardia were higher in group D. ${ }^{27} \mathrm{In}$ another study with $0.4 \mathrm{mg} / \mathrm{kg}$ Labetalol 5 minutes prior to laryngoscopy and intubation researchers found signficantly lower HR from induction through 1 minute following intubation in labetalol group. While in MAP there was significant increase in both groups. They concluded that labetalol blunted the HR response but had minimal effect on blood pressure. $^{18}$

Its onset of action is 5 minutes and reaches its peak effect at 5-15 minutes after intravenous injection and rapidly redistributes having redistribution half life of 5.9 minutes. ${ }^{22,28,12}$ We had done pin insertion within 10 to 15 minutes after injection of labetalol in this study as it has a peak effect in 5-15 minutes after administering IV and is redistributed very rapidly.

Inada et al used $10 \mathrm{mg}(0.14 \mathrm{mg} / \mathrm{kg})$ labetalol and found it ineffective in attenuating pressure response. ${ }^{19}$ This might be because they had used lower dose of labetalol and given only 2 min prior to intubation. Because of which the peak effect of drug was lost at intubation. Maharaj et $\mathrm{al}^{28}$ also found 0.25 and $0.5 \mathrm{mg} / \mathrm{kg}$ Labetalol ineffective in blunting of blood pressure response but they had not mention the timing of giving the drug. Leslie at $\mathrm{al}^{24}$ used labetalol in doses of $0.25,0.5,0.75$ and $1.0 \mathrm{mg} / \mathrm{kg}$ and found all doses effective in controlling the rise in RPP at laryngoscopy. Kim et $\mathrm{al}^{29}$ reported that a single dose of labetalol $0.25 \mathrm{mg} / \mathrm{kg}$ given 5 minutes before induction decreases HR significantly after intubation upto 10 minutes. Ramanathan et $\mathrm{al}^{12}$ successfully used $20 \mathrm{mg}$ labetalol and found attenuation of the haemodynamic response to laryngoscopy and intubation in preeclamptic patients.

Possible adverse effects include bradycardia and hypotension. Bradycardia was observed in $28 \%$ of patients after 10 minutes in labetalol group and treated with atropine in $0.2 \mathrm{mg}$ increments. They did not found recurrent episodes of bradycardia. ${ }^{22}$ We did not encounter bradycardiac episode might be because of pin insertion stimulus at that time.

\section{Conclusion}

Addition of a single dose of Labetalol 5 minutes prior to intubation to fentanyl gives better control of hemodynamic response to intubation and skull pin insertion during neurosurgery. There was no increased risk of bradycardia or hypertension.

\section{References}

1. Sidhesh Bharne, Prasanna Udupi Bidkar, Ashok Shanker Badhe, Styen Parida, Andi Sadayandi Ramesh.

"Comparion of intavenous labetalol and bupivacaine scalp block on the hemodynamic and entropy changes following skull pin application: A randomized open lable clinical trial" Asian Journal of Neurosurgery vol 11, Issue 1, January- March2016,60-5.

2. Hillman DR, Rung GW, Thompson WR, Davis NJ. "The effect of bupivacaine scalp inffilteration on the hemodynamic response to craniotomy under general anesthesia" Anesthesiology 1987;67:1001-3.

3. Uyar AS, Yagmurdur H, Fidan Y, Topkaya C, Basar H. "Dexmedetomidine attenuates the hemodynamic and neuroendocrinal responses to skull-pin head-holder application during craniotomy" J Neurosurg Anesthesiol 2008;20:174-9.

4. Anu Paul, Handattu Mahabaleswara Krishna. "Comparison between intravenous dexmedetomidine and local lignocaine infilteration to attenuate the haemodynamic response to skull pin head holder application during craniotomy" Indian Journal of Anaesthesia ; vol. 59, issue 12, Dec 2015.

5. Costello TG, Cormack JR. "Clonidine premedication decreases hemodynamic responses to pin head-holder application during craniotomy" Anesth Analg 1998;86:1001-4. 
6. Smith FJ, van der Merwe CJ, Becker PJ. "Attenuation of the haemodynamic response to placement of the Mayfield skull pin head holder. Alfentanil versus scalp block" South Afr J Anaesth Analg 2002;8:4-11.

7. Jamali S, Archer D, Ravussin P, Bonnafous M, David P, Ecoffey C. "The effect of skull -pin insertion on cerebrospinal fluid pressure and cerebral perfusion pressure: influence of sufentanil and fentanyl" Anesth Analg 1997;84:1292-6.

8. Doblar DD, Lim YC, Baykan N, Frenette L. “A comparison of alfentanil, esmolol, lidocaine, and thiopental sodium on the hemodynamic response to insertion of headrest skull pins" J Clin Anesth 1996:8:315 .

9. Ayse Mizrak, Ibrhim Erkutlu, Mehmet Alptekin, Elzem Sen, Murat Geyik, Abdulvahab Gok, Unsal Oner. "Efficacy of Fentanyl and/or Lidocaine on Total Antioxidants and Total Oxidants duting craniotomy" Clinical Medicine \& Research vol 9, Number 2:82-7.

10. Babita, Singh B, Saiyed A,Meena R, Vrma I, Vyas CK. "A comparative study of labetalol and fentanyl on the sympathomimetitic response to laryngoscopy and intubation in vascular surgeries" Karnataka Anaesth J 2015;1:64-8.

11. Goldberg ME, McNulty SE, Azad SS, Cantillo J, Torjman M, Marr AT, Huffnagle S, Seltzer JL. "A comparison of labetalol and nitroprusside for inducing hypotension during major surgery" Anesth- Anal 1990;70:537-42.

12. Ramanathan J, Sibai B M, Mabie W C, Chauhan D, Ruiz A G. "The use of labetalol for attenuation of hypertensive response to endotracheal intubation in preeclampsia" Am J Obsteh Gynecol 1988;159:650-4.

13. Martin DE, Rosenberg H,Aukburg SJ, Bartkowski RR, Edwards MW Jr, Greenhow DE, et al. "Low-dose fentanyl blunts response to tracheal intubation" Anesthe Analg 1982;61:680-4.

14. Kayhan Z, Aldemir D, Mutlu H, Ooup E." Which is responsible for the haemodynamic response due to laryngoscopy and endotracheal intubation? Catecholamine, vasopressin or angitensin?" Eur J Anaesthesiol 2005;22:780-5.

15. Doblar DD, Lim YC, Baykan N, Frenette L. “A comparison of alfentanil, esmolol, lidocaine and thiopental sodium on the hemodynamic response to insertion of headrest skull pins" J clin Anesth 1996;8:315.

16. Zargar JA, Zargar IA, Mehraj-ud-din, Zargar SA, Mehrajud-din. "Effect of metoprolol and esmolol on rate pressure product and ECG changes during laryngoscopy and tracheal intubation in controlled hypertensive patients" Indian J Anaesth.2002;46:365-8.

17. Magnusson J, Werner O. Carlsson C, Norden N, Pettersson KI. Metoprolol, fentanyl and stress response to micro laryngoscopy. "Effect on arterial pressure, heart rate and plasma concentration of catecholamines. ACTH and cortisol" Br. J. Anesthesio 1983;55:405-14.

18. Chung KS, Sinatra RS, Chung JH. "The effect of an intermediate dose of labetalol on heart rate and blood pressure response to laryngoscopy and intubation" J Clin Anesth. 1992;4:11-5.

19. Inada E, Cullen DJ, Nemeskal R, Teplick R. "Effect of labetalol on the hemodynamic response to intubation: acontrolled randomized double-blind study" J Clin Anesth 1989;1:207-13.

20. K.S. Olsen, L.B. Svendsen, F.S.Larsen and O.B.Paulson. "Effect of labetalol on cerebral blood and autoregulation in healthy humans" British journal of Anaesthesia 1995;75:51-4.

21. Meftahuzzaman SM, Islam MM, Ireen ST, Islam MR, Kabir H, Rashid H, Uddin MZ. "Comparison of efficacy of labetalol and fentnyl for attenuating reflex responses to laryngoscopy and intubation" Mymensingh Med J. 2014 Apr;23(2):242-8.

22. Sarvesh P.Singh, Abdul Quadir, Poonam Malhotra. "Comparison of esmolol and labetalol, in low doses, for attenuation of sympathomimetic response to laryngoscopy and intubation" Saudi J Anaesth 2010;SepDec;4(3):163-8.

23. Yeasmeen S, Siddique MRU, Islam A, Akaruzzaman A, Banik D, Hye A. "Use of labetalol and glyceryl trinitrate for induced hypotension in spine surgery. A comparative study" J Bangladesh Soc Anaesthesiol 2014;22:48-53.

24. John B. Leslie, Robert W. Kalayjian, Thomas M. McLoughlin, John R. Plachetka. "Attenuation of the hemodynamic responses to endotracheal intubation with preinduction intravenous labetalol" Journal of clinical anesthesia 1989; vol. 1, Issue 3,194-200.

25. Chung KS, Raymond S, Jonathan D. "A comparison of fentanyl, esmolol and their combination for blunting the haemodynamic response" Anaesth Analg 1991;72:482-6.

26. Gupta S, Tank P. "A comparative study of efficacy of esmolol and fentanyl for pressure attenuation during laryngoscopy and endotracheal intubation" Saudi J Anaesth 2011;5:2-8.

27. Alka Kevalramani, Seema Partani, Nagendra Prasad Sharma, Venus Sharma. "Comparison of Labetalol versus dexmedetomidine to assess the haemodynamic responses to laryngoscopy and intubation during induction of general anaesthesia- a prospective, randomized controlled study" Indian Journal of clinical Anaesthesia,2016;3(4):512-7.

28. Maharaj RJ, Thompson M, Brock-utne J G, Williamson $\mathrm{R}$, Downing W. "Treatment of hypertension following endotracheal intubation" S A Medical Journal 1983;63:691-4.

29. Kim SS, Kim JY, Lee JR, Song HS. "The effects of verapamil, labetalol and fentanyl on hemodynamic responses ti endotracheal intubation" Korean J Anesthesiol 1994;27:143-54. 